\title{
Winners of the competition for the best original article published in REUMATOLOGIA in 2015
}

REUMATOLOGIA Golden Pen for the study

Assessment of the usefulness of skin autofluorescence as an indicator of disease activity and of the risk of developing diabetes in patients suffering from rheumatoid arthritis

Pawet Żuchowski, Katarzyna Kolossa, Stawomir Jeka, Rafat Wojciechowski,

Arnika Wilinska-Jankowska, Marzena Waszczak

REUMATOLOGIA Golden Pen for the study

Assessment of the level of vaccine-induced anti-HBs antibodies in children with inflammatory systemic connective tissue diseases treated with immunosuppression

Izabela Szczygielska, Elżbieta Hernik, Małgorzata Kwiatkowska, Lidia Rutkowska-Sak,

Beata Kotodziejczyk, Agnieszka Gazda

REUMATOLOGIA Silver Pen for the study

The relationship between the presence of autoantibodies, indicators of local and systemic inflammation, the serum concentration of B-cell activating factor and the intensity of salivary gland infiltration

in patients with primary Sjögren's syndrome

Maria Maślinska, Ewa Kontny, Brygida Kwiatkowska

REUMATOLOGIA Bronze Pen for the study

Influence of biologic therapy on growth in children with chronic inflammatory connective tissue diseases

Joanna Świdrowska-Jaros, Agnieszka Zygmunt, Matgorzata Bernacka-Zielińska,

Jerzy Stańczyk, Elżbieta Smolewska

Certificates of recognition for the most active reviewers in 2015 were awarded to:

Maria Majdan, Bożena Moskalewicz,

Mariusz Puszczewicz, Małgorzata Wistowska

On behalf of the Committee

Eugeniusz J. Kucharz 